\title{
A FILOSOFIA E A MÁQUINA DE FAZER ÍNDICES*
}

\author{
Sérgio Lima dos Santos Nastasi**** \\ Universidade Federal do ABC (UFABC) - São Bernardo do Campo - São Paulo
}

\begin{abstract}
RESUMO
O presente texto visa a problematização do ensino de Filosofia na Educação Básica em um contexto de maior enquadramento do trabalho docente nas escolas públicas do estado de São Paulo. Argumenta-se que o poder educacional vem transformando as escolas em máquinas de fazer índices, em detrimento das experiências mínimas ou dos disparadores de pensamentos e afetos no cotidiano dos encontros aprendentes. Para tanto, mobilizam-se conceitos de Gilles Deleuze, Gilles Deleuze e Félix Guattari e Georges Didi-Huberman a fim de pensar as possibilidades da Filosofia na escola.
\end{abstract}

Palavras-chave: Filosofia. Educação. Filosofar. Ensino-aprendizagem. Possibilidade.

1. 0 que quero indagar esta noite com vocês pouco terá a ver com uma rigorosa definição de educação e do filosofar. Embora a discussão que pretendo traçar neste encontro perpasse alguns componentes do que percebemos por essas palavras sabemos que, na maioria das vezes ou quase sempre, nunca estamos falando das mesmas coisas. Isso já deve gerar um alívio em vocês e, ao mesmo tempo, uma angústia por

* Palestra proferida na II Semana de Filosofia da Metodista: "Filosofia e Educação: é possível Educação sem Filosofar?”. São Bernardo do Campo, SP, 14-17 out. 2019. Optei por manter a coloquialidade das expressões usadas ao longo do encontro.

** Mestre em Filosofia pela Universidade Federal do ABC (UFABC).

E-mail: sergio.nastasi@ufabc.edu.br 
não termos quase nada para se agarrar no pensamento. Por isso começarei com algumas noções anexatas até atingir alguma consistência ao longo desta fala. Ou seja, tentarei aqui dar um corpo ao que mais me chamou a atenção nessa temática: o problema da possibilidade.

Então, para afinar a nossa conversa, para buscar uma tonalidade comum entre nós e preparar nossos ouvidos, esboçarei duas hipóteses: se, por um lado, considerarmos o filosofar como modo de expressão separado da filosofia, seria possível admitir que outras matérias também possam ensinar a filosofar, sendo a filosofia algo totalmente dispensável da educação. Dito isto, é bem fácil deduzir que educação sem filosofar seria impossível - e educação sem filosofia seria possível. Por outro lado, se pensarmos o filosofar como modo de expressão inseparável da filosofia, somente ela poderia nos dar essa coisa (estou usando a palavra coisa porque ela tem a virtude da indefinição). Dessa maneira, educação sem filosofar seria impossível ao excluirmos a filosofia, uma vez que as demais matérias não seriam capazes de filosofar.

Antes de avançar é importante assinalar um pressuposto contido nessas duas hipóteses aparentemente excludentes, qual seja, que a educação se constitui de um conjunto de matérias ensináveis, o que reduz nossa noção de educação à escolarização fragmentada. Dito de outra forma, parto de algo muito mais parecido com a ideia corrente que se tem de educação, aquela quase completamente reduzida ao âmbito escolar.

Podemos entender escolarização fragmentada como a oferta de uma instrução básica (ler, escrever e contar) aliada a um pequeno repertório de curiosidades científicas e artísticas, numa hierarquia de necessidades. Não só há conteúdos mais ou menos prescindíveis, como também há matérias mais ou menos prescindíveis. E a filosofia, vira e mexe, está nessa zona. Trata-se, aqui, do que as crianças e adolescentes devem ou não aprender. Há toda uma gestão para estabelecer isso (as políticas públicas...) fazendo com que possamos compreender, literalmente, a célebre frase do cineasta Godard: "As crianças são prisioneiros políticos". 
2. Contudo, reservarei essa discussão para depois, porque agora, com essas duas hipóteses do filosofar começo a abrir o problema da possibilidade, mas da possibilidade do próprio problema. Em outras palavras: por que é possível colocar o problema da possibilidade da educação sem o filosofar? Estamos diante de um falso problema? Este é um problema comum às demais matérias?

Um falso problema, como nos mostrou Deleuze (2012) a partir dos conceitos de Henri Bergson, se caracteriza por suas soluções previsíveis, respostas que se sabe de antemão ou por termos mal formulados que servem como armadilhas ao pensamento. Assim, será preciso avaliar se o problema dado já indica se sabemos previamente qual linha deveremos seguir, se a resposta salta aos olhos, se ele posiciona a gravidade de sua interrogação muito mais na negação que na afirmação, ou muito mais na ausência que na presença.

Desde a primeira vez que li a pergunta-tema desse evento notei que ela soa como algo da ordem do "onde já se viu" ou da ordem do "será o Benedito". Ela muito bem poderia ser escrita assim: onde já se viu educação sem filosofar? Mas será o Benedito? Há aí um afeto de indignação. Estamos todos indignados com a impossibilidade, com a impotência! Queremos fazer filosofia e nos vêm uma impotência. Entretanto, como já sabemos que a educação com o filosofar é possível, estamos livres para criar uma variação e propor uma nova pergunta: como se dão os possíveis que a filosofia abre na educação?

3. Até aqui já pensei com vocês em duas operações distintas: com a primeira poderemos explorar até o limite de nossas forças (e do tempo!) as hipóteses da separabilidade/inseparabilidade do filosofar da filosofia, mobilizando uma mínima definição de educação e do que é possível em educação. A segunda operação problematiza a própria pergunta e nos faz desconfiar de sua suficiência conceitual para, enfim, propor a reformulação do problema.

Talvez seja mais interessante fazer entrecruzar essas duas operações: partir da nova pergunta sem abandonar os elementos postos pelas hipóteses ensaiadas. Digo isso porque suspeito que o filosofar seja inseparável da filosofia e não me parece que este seja um problema co- 
mum às demais matérias, ao menos no cotidiano da nossa experiência em educação.

Quero dizer que, ainda que outras matérias pensem o seu ensino, este é separado daquilo que posso chamar de essência da matéria. Vou me explicar: o ensino de matemática, por exemplo, não é um problema matemático, ou o ensino de química, sociologia, geografia não se configura como um problema químico, sociológico ou geográfico. Também aqui não se pergunta em educação sem quimicar, sociologizar ou geografar... Seja lá o que isso queira dizer. Talvez a filosofia seja a única matéria que coloca seu ensino como um problema essencialmente filosófico. Por isso, suspeito que o que chamamos de filosofar seja um modo de expressão inseparável da filosofia.

Posso extrair da minha experiência como professor de filosofia e de relatos de outros amigos um elemento que reforça essa noção de inseparabilidade. Volta e meia escuto (e eu mesmo já disse coisas parecidas quando era um estudante no Ensino Médio) que quando chega a aula de filosofia é possível "brisar": "Nossa, mó brisa isso, né, professor?" é o que já ouvi inúmeras vezes ao apresentar conceitos em aula. Compreendo essa frase e suas variações de maneira literal. A filosofia traz a brisa de pensamentos novos, oxigena o pensar, abre uma fresta por onde passa um frescor violentamente delicado. Assim os estudantes vão notando que, em filosofia, palavras são mais que palavras. Eis o início e o sentido do que chamo de uma Aula-Várzea, um bom e fértil encontro aprendente.

4. Agora sinto que já estou seguro, depois de dar uma espanada nos termos do problema inicial, para desenvolver algo sobre essa fertilidade da filosofia em educação. Por que isso é tão importante? Porque ao colocar a pergunta sobre a possibilidade, suscito o que há de potente na filosofia: sua natureza criadora. Ou melhor: se a filosofia está sendo colocada em xeque, assim como outras formas de pensamento criadoras de possíveis, é porque ela é um acontecimento!

Gostaria de insistir nisso com vocês hoje, porque me parece que a intenção de desidratar ou mesmo de excluir a filosofia dos currículos oficiais do que chamamos de educação básica talvez seja um forte sinal de que a filosofia é um acontecimento nas escolas! 
Como se nota, é com bastante alegria que deveríamos saber que a filosofia continua a incomodar e a "entristecer os tolos". Alegria esta contida no texto célebre e já muito instangrável de Gilles Deleuze:

Quando alguém pergunta para que serve a filosofia, a resposta deve ser agressiva, visto que a pergunta pretende-se irônica e mordaz. A filosofia não serve nem ao Estado, nem à Igreja, que têm outras preocupações. Não serve a nenhum poder estabelecido. A filosofia serve para entristecer. Uma filosofia que não entristece a ninguém e não contraria ninguém, não é uma filosofia. A filosofia serve para prejudicar a tolice, faz da tolice algo de vergonhoso. Não tem outra serventia a não ser a seguinte: denunciar a baixeza do pensamento sob todas as suas formas. Existe alguma disciplina, além da filosofia, que se proponha a criticar todas as mistificações, quaisquer que sejam sua fonte e seu objetivo? (DELEUZE, 2018, p.134)

Percebam como Deleuze marca os poderes estabelecidos, o Estado, a Igreja, a tolice e todas as formas de baixeza do pensamento e nos faz pensar que a filosofia não é "chapa branca”, ela tem de encarar muitos atravessadores para abrir campos de possíveis e começar a criar conceitos. A questão então é a seguinte: quais são os nossos atravessadores? Quem ou o que se interpõe em nosso caminho?

5. Darei um salto agora para pensar um contexto mais específico para nós e em seguida ampliá-lo. Nos últimos vinte anos, mais ou menos, na rede estadual das escolas públicas de São Paulo, vem se consolidando uma forma de organização do poder educacional que transforma as escolas em verdadeiras máquinas de fazer índices. Com ela há toda uma semiótica dominante a codificar o ensino em determinadas competências e habilidades, este par de palavras que nos dá uma comichão instantânea. Tal codificação se arranja em provas, planos, projetos, metodologias, gestão etc.; toda a vitalidade escolar deve ser absorvida, em grau maior ou menor, aqui e ali, por essa codificação, por esse regime de signos.

Com o passar do tempo, alguns dispositivos dessa máquina tornaram-se mais sofisticados, intensificando as tentativas de enquadramento do fazer docente, tudo em nome do desempenho, dos núme- 
ros que representariam e comprovariam os avanços ou retrocessos na qualidade do ensino de cada unidade escolar. Ou seja, estes dispositivos são mecanismos de captura.

Mergulhados numa cultura de ranqueamento meritocrático, as trabalhadoras e os trabalhadores em educação se veem instados a competir entre si por melhores números e posições numa área em que o controle sobre os meios e os resultados escapa de suas mãos a todo momento (se é que há algum controle...). Em troca, podem ganhar, como os aparelhos celulares, um bônus não incorporado em seus raquíticos salários. A contagem para estabelecer esse prêmio é sempre confusa, quase ininteligível - precisaríamos chamar apontadores de jogo do bicho para decifrá-la. Isso parece ampliar a sensação frequente de frustração com a carreira docente, sobretudo porque temos uma tendência para eleger apenas uma única causa explicadora de situações complexas, como se o Aristófanes explicasse o Ari Toledo! Assim, o discurso que se hegemoniza nas reuniões de planejamento nas escolas (e fora delas...) consagra o professor como protagonista dos fracassos. $\mathrm{Ou}$ ao menos pelo o que se entende por fracasso.

6. Mas o que a máquina de fazer índices produz? E quando digo máquina, inspirado claramente em Gilles Deleuze e Félix Guattari (2010), digo algo literal. É literalmente que a escola é hoje uma máquina de fazer índices. E a respeito da sua produção, percebo algo que vem se aprimorando: a máquina faz a transcendência entrar no processo de ensino-aprendizagem. 0 que quero dizer com isso é bem simples: quando as provas externas ${ }^{1}$ (e mesmo as provas internas) são consideradas como o grande objetivo do trabalho, racha-se o processo em dois, separa-se em dois planos paralelos, mas hierarquizados. Negligencia-se assim o que há de mais cotidiano nos encontros aprendentes, e as experiências mínimas ou os disparadores de pensamentos e afetos não obtém a menor importância.

\footnotetext{
1 Refiro-me, a nível estadual, ao Sistema de Avaliação do Rendimento Escolar do Estado de São Paulo (SARESP), à Avaliação da Aprendizagem em Processo (AAP) e à Avaliação Diagnóstica Complementar (ADC); a nível nacional: Sistema de Avaliação da Educação Básica (SAEB) e Exame Nacional do Ensino Médio (ENEM).
} 
Esse cenário desolador que desenho neste momento já deve fazer com que vocês compreendam aquelas palavras de Godard citadas minutos atrás com um sentido mais denso: "as crianças são prisioneiros políticos” de adultos que também são prisioneiros políticos.

Dito isto, consigo finalmente reentrar com o problema da possibilidade da filosofia em educação. Dizia que a filosofia abre possíveis e, com Deleuze, vimos que ela não serve a poderes estabelecidos e denuncia todas as formas de baixeza do pensamento, as mistificações etc. A filosofia abre possíveis porque é criadora.

A nossa alegria nesse contexto de desolação, é que a filosofia é uma matéria indócil. Portanto, ela está para além de um certo ideal romântico-instrumental (ideal partilhado também pela sociologia e pela história): que seria o de formar cidadãos críticos/reflexivos que ajudem a transformar o mundo que vivem, como se as demais formas de pensamento não pudessem produzir crítica e reflexão.

A nossa alegria consiste também em saber que todo sistema de dominação tem seus furos. Por isso a filosofia deve ser capaz, ao mesmo tempo, de oxigenar o pensamento e dar um corpo às experiências mínimas que são duramente negligenciadas nas escolas. Podemos ser capazes de pensar a educação para além da escolarização fragmentada e do ensino integral pasteurizado.

Por que afirmo essas coisas? Porque há toda uma dimensão poética, onírica, erótica, todo um mundo insubmisso e errante dos prazeres fluindo pela escola (e pelas ruas) que espreitam pelas frestas, pelos furos. São os "vaga-lumes" e sua "claridade menor", como já escreveu o filósofo Georges Didi-Huberman (2014), diante da "claridade ofuscante" dos índices de desempenho e qualidade, e dos discursos dominantes. Para Didi-Huberman, é preciso aguçar a sensibilidade para ver os vaga-lumes e sua "luz menor".

Daí a necessidade de uma luta política em que os mínimos gestos contam. Uma luta política não por uma precária sobrevivência ou para não "perder mais", como se diz nos sindicatos. Todavia, manter-se na vibração da pergunta-tema dessa Semana de Filosofia e seu indignado "onde-já-se-viu ". É um grito, é um gesto político contra a tolice. 0 que está sendo feito aqui (sem qualquer "rasgação de seda") entristece 
aqueles que acreditam num mundo em que só há uma forma de compreender a realidade. Continuemos!

\section{REFERÊNCIAS}

DELEUZE, G. Nietzsche e a filosofia. São Paulo: n -1 edições, 2018. Bergsonismo. São Paulo: Editora 34, 2012.

DELEUZE, G.; GUATTARI, F. O Anti-Édipo: Capitalismo e Esquizofrenia. São Paulo: Ed. $34,2010$.

DIDI-HUBERMAN, G. A sobrevivência dos vaga-lumes. Belo Horizonte: Editora UFMG, 2014. 